\title{
Marketed under Biologic License Application
}

National Cancer Institute

\section{Source}

National Cancer Institute. Marketed under Biologic License Application. NCI Thesaurus.

Code C73585.

A category specifying that a product is marketed under a Biologic License Application. 